\title{
Psychometrics of Persian Version of the 11 items De Jong Gierveld Loneliness Scale among an Iranian Older Adults Population during COVID-19 Pandemic
}

\author{
Lida Hosseini \\ Iran University of Medical Sciences
}

Hamid Sharif Nia

Mazandaran University of Medical Sciences

Erika Sivarajan Froelicher

University of California, San Francisco

Mansoureh A. Farahani ( $\nabla$ m_negar110@yahoo.com )

Iran University of Medical Sciences

\section{Research Article}

Keywords: social loneliness, emotional loneliness, Psychometrics, validity, reliability

Posted Date: February 15th, 2021

DOl: https://doi.org/10.21203/rs.3.rs-191913/v1

License: (a) (i) This work is licensed under a Creative Commons Attribution 4.0 International License. Read Full License 


\section{Abstract}

Background: Due to the urgent emphasis on quarantine during the COVID-19 pandemic, the possibility of feelings of loneliness, especially in older adults, became an important nursing priority. Therefore, is important to identify loneliness quickly and respond appropriately to prevent, reduce or treat it. In order to do so, the aim of this study was to translate and evaluated the Persian version of De Jong Gierveld Loneliness Scale for older adults.

Method: The original scale was translated into Persian using the World Health Organization protocol of forward-backward translation technique. Face validity and content validity; followed by EFA and CFA. The sample was 400 olddr adults including who were recruited via online data gathering. Lastly, reliability was assessed through the Average Inter-Item Correlation (AIC), Cronbach's alpha and McDonald's omega.

Results: The results showed that Persian version of Loneliness Scale had two factors namely social loneliness (5 items) and emotional loneliness ( 3 items) and the combined score explained $45.66 \%$ of the total variance of this scale. In addition, all goodness of fit indices confirmed a two factors model fit and all of the reliability indices were excellent.

Conclusion: The Persian version of the Loneliness Scale is useful and suitable for detecting social loneliness and emotional loneliness in older adults during the COVID-19 pandemic.

\section{Background}

In December 31, 2019, 27 cases of pneumonia with unknown cause were reported from Wuhan Province. Then, on January 7, 2020, Chinese authorities announced the identification of a new type of viral disease of the SARS virus family, called severe acute respiratory syndrome coronavirus 2 (SARS-CoV-2), which spread rapidly worldwide in 2019 and led to a public health emergency of international concern. On February 11, the World Health Organization (WHO) named this viral pandemic as Coronavirus in 2019 (COVID-19) (1).

On February 19, two deaths due to the COVID-19 virus were reported in Qom, Iran (2). The coronavirus spread was so rapid in Iran that by March 5, 2020, the virus had spread to all 31 provinces of Iran (3). According to the latest statistics of the WHO on October 17, 2020, the total number of confirmed cases were 522,387; and the total number of confirmed deaths was 29,870 (4).

Because there is insufficient experience and knowledge about this disease, various treatments previously used to treat other types of coronavirus were limited. Treatments that were used for SARS-CoV and MERS, to control COVID-19, including antiviral drugs, immune suppressant, steroids, plasma from recovered patients, Chinese medicine and psychiatric support are recommended (5). Since this disease is transmitted through respiratory droplets, the main way to control the spread of this virus in the population is wearing masks, rigorous hand washing hygiene and social distancing, self-isolation and quarantine (6). 
Social distancing, quarantine, and self-isolation can significantly change people's daily lives and lead to immediate disruption of physical, social and economic functions and can lead to specific mental health and psychological problems for persons, especially in vulnerable groups such as older adults (7). So that, Based on a literature review, common psychological problems following quarantine, especially in older adults include anxiety, depression, and increased loneliness $(3,8,9)$. In the meantime, the issue of loneliness is an important issue because even before the coronavirus crisis, loneliness was a public health issue and a major concern in the elderly. Studies have shown that $35 \%$ of adults 45 years and older and $43 \%$ of adults over 60 years' experience loneliness at least "sometimes" (10).

Studies have shown that loneliness is associated with numerous physical and psychological problems in older adults, so that it increased $29 \%$ risk of heart disease, $32 \%$ risk of stroke, $50 \%$ risk of dementia $(8,11)$, low self-esteem, fatigue, depression (12), lack of goals, unpleasant thoughts, negative thoughts, suicidal thoughts, thoughts of death (13), social disorders, loss of social interaction, sleep and anxiety disorders, frustration, mobility limitation $(14,15)$ and increased mortality $(15)$. Totally, a strong association has been observed between loneliness and depression (16).

Given the importance of the issue of loneliness, Weis (1973) made a distinction between two dimensions of loneliness namely emotional loneliness and social loneliness (17). Social loneliness means the mental assessment of a situation in which the person finds the level of relationships with their friends and colleagues is less than desirable. Emotional loneliness refers to the lack of existence of others and relatives to whom one is emotionally dependent. In fact, emotional loneliness is more about family status (18). Weis proposed that the effects of either of these two loneliness domains could be different. For example, he stated that emotional loneliness leads to feelings of aloneness, anxiety, over-monitoring, hypersensitivity to minimal symptoms, and feelings of abandonment. In contrast, social loneliness is associated with boredom, depression and aimlessness. Also, the type of loneliness varies from person to person depending on their demographic characteristics and their conditions (19). In general, it has been shown that in both types of loneliness, the existence of a specific severity of deprivation was considered as the essence of loneliness (15).

Duo to the necessity of the quarantine during the COVID-19 pandemic, there is a greater likelihood of increasing feelings of loneliness, especially in the older adults. Also, globally, older people require health care system more often than the younger population. Nurses have the most contact with this population in the health care system and they are well positioned to identify older adults at risk of loneliness and its severity. To create appropriate clinical and public health interventions for loneliness to prevent, reduce, or treat of loneliness. For this purpose, there is a need to identify a reliable and valid scale to assess the concept of "loneliness" accurately. One of the most important scales recently used to measure this problem in the individuals is the De Jong Gierveld Loneliness Scale, developed in 1985 (20). This scale consists of 11 items that examine the feelings of loneliness and the distinction between social and emotional loneliness. Of the 11 items, 6 items are used to measure emotional loneliness with negative semantic load and 5 items are used for social loneliness with sentences using positive semantic load. The validity and reliability of this scale have been evaluated in several European and Asian countries, however, not in Iran. Due to an increasing elderly population, greater attention to youth and adolescents, inappropriate attitudes 
toward the elderly, the rate of social isolation and loneliness is high in the Iranian older adults population (21). In addition, the emphasis on quarantining most of these people during the COVID-19 pandemic has made them more prone to loneliness. Therefore, considering the importance of loneliness in the older adults during quarantine in this pandemic. There is a need to accurately identify distinguish its types of loneliness from each other. Because there is an important difference between feeling lonely "due to losing someone" and feeling lonely "due to the lack of a social network", their side effects differ, and the focus of the interventions are also differ depending on the type of loneliness (22). The aim of this study was to culturally translate and adapt the instrument and evaluate the psychometric properties of the Persian Loneliness Scale. The reasons for choosing this scale were simplicity, brevity, practicality, comprehensiveness, and to be able to distinguishing the two different types of dimensions of loneliness were important.

\section{Methods}

\section{Design}

This study uses with methodological cross- sectional design. The aim of this study was to translate and evaluate the psychometric properties and the feasibility of a Persian version of the " 11 items De Jong Gierveld Loneliness Scale".

For performing this study, we selected our samples among older adult people of Tehran with this inclusion criteria: older adults over 65 years, have the ability to use social networks, have a minimum literacy, have a consent to participate in the study via written consent, and be Iranian and fluent in Persian, and older adults without cognitive and memory problems.

\subsection{Measurement}

We used two questionnaires including demographic questionnaire and Persian version of De Jong Gierveld Loneliness Scale in this study. The demographic questionnaire was composed of personal information including age, gender, marital status, educational level, economic status, employment status, and number of children. The original Loneliness Scale assessed the status of loneliness. This 11 -item scale includes two factors: social loneliness (5 items) and emotional loneliness (6 items). This scale is useful because it examines feeling of loneliness and distinguishes between social and emotional loneliness. The Loneliness Scale uses response options on a 5-point Likert-type scale, where $0=$ None of the time, and $4=$ All of the time (23).

\subsection{Translation}

The process of translation and back translation used in the development of the Persian version of this scale was based on the WHO protocol of forward-backward translation technique (24). First, we obtained the written permission from the developer of the scale "Professor De Jong Gierveld "via e-mail for the 
process of translation and validation of the questionnaire. Second, we invited two English-Persian translators to translate the Loneliness Scale independently. Third, two Persian translations of the questionnaire were reviewed and evaluated by an expert panel (including some of this paper's authors (H.SH and M.F) as well as two professional translators) and after reviewing both translations and discussing the differences between them, we created a single Persian version of this questionnaire. Fourth, two English -Persian translators (unlike the first two translators) who had no knowledge of the English version of the questionnaire, back-translated the Persian version back into English. Lastly, an expert panel reviewed the two English back-translations. After the necessary revisions and adjustments, the final English version was sent to De Jong Gierveld for confirmation by email.

\subsection{Face validity}

Face validity was established using both qualitative and quantitative methods. For the qualitative step, we gave the scale to 10 older adults aged over 65 years and asked them to comment on the appropriateness of the appearance, degree of clarity and ambiguity of the selected words and the rational for the sequence of the items in order to achieve the goals of the scale. These viewpoints were included in the final version. Then the final version was assessed using quantitative face validity by measuring item impact scores. In order to perform this phase of validity, 10 target population members were asked to rate items on a fivepoint scale; where $5=$ quite important, 4 = somewhat important, $3=$ medium important, 2 = slightly important, and $1=$ not at all important. An impact score greater than 1.5 is considered appropriate. The impact score was calculated using the following formula: (Impact score=frequency (\%) importance) (25).

\subsection{Content validity}

Both qualitative and quantitative methods were used to calculate content validity. In order to determine the quality of content validity, indicators such as grammar, use of appropriate words and item allocation were evaluated by reviewing the opinions of 10 measurement experts in the fields of measurement, psychology and aging. In addition, to assess the content validity quantitatively, we measured content validity ratios (CVR) and content validity index (CVI) via modified kappa coefficient (K). To calculate CVR, the questionnaire was administered to 10 persons representing education and psychometrics, psychology and aging were asked them to evaluate how essential each items on a three-point scale as follows: 1=Not essential, 2=Useful but not essential, and $3=$ Essential $(26,27)$. Then the CVR was evaluated using the following formula: $\mathrm{CVR}=(\mathrm{ne}-[\mathrm{N} / 2]) /(\mathrm{N} / 2)$. In this formula, $\mathrm{nE}$ is the number of experts who consider an item essential and $\mathrm{N}$ is the total number of experts' panel. Since the number of expert panel was 10 , based on Criterion in the Lawshe table, the minimum acceptable CVR is equal to 0.62 (28). Also Items relevancy of the 11 -items scale was evaluated by 10 experts on a four-point scale as follows: $1=$ irrelevant, $2=$ somewhat relevant, 3 = quite relevant, $4=$ highly relevant. For evaluation CVI, the modified kappa coefficient $(\mathrm{K})$, which is an important complement to $\mathrm{CVI}$, was calculated to determines the degree of chance agreement of experts and eliminate of chance effect for each item was evaluated using the 
following formula: $\mathrm{K}=(\mathrm{I}-\mathrm{CVI}-\mathrm{PC}) /(1-\mathrm{Pc})$. Evaluation criteria for Kappa is as follows: good $=0.60-0.74$ and the excellent value of Kappa $>0.75$. (29).

\subsection{Construct validity}

Construct validity was evaluated using Exploratory Factor Analysis (EFA) Confirmatory Factor Analysis (CFA) and Convergent and Divergent Validity. Based on this criterion for factor analysis, 10 subjects for each item of scale were needed. Thus, a sample of 200 older adults was considered sufficient for each two stages of EFA and CFA (30). In this study, we used De Jong Gierveld Loneliness Scale with 11 items. We also gathered data via online data gathering. We created the online questionnaire via Google Forms and sent its URL link by email or social networking applications such as a Telegram channel or WhatsApp for target population. Then Data were extracted from Google Form in the Excel file and prepared for analysis.

\subsubsection{Exploratory Factor Analysis}

EFA was performed with Maximum Likelihood Exploratory Factor Analysis (MLEFA) with varimax rotation. The quality of response and quality of samples was calculated with Kaiser-Meyer-Olkin (KMO) and Bartlett test, where acceptable values for $\mathrm{KMO}$ index are greater than 0.7 . Furthermore, $95 \%$ confidence intervals (Cls) were estimated for each eigenvalue based on $\mathrm{Cl} 95$ width (z:1.96). Also Horn's parallel analysis approach was used to determine the number of latent factors that items with communalities $<0.2$ were excluded from EFA (31). The number of extracted factors was determined based on tree modern approach: a) Exploratory Graph Analysis (EGA), b) parallel analysis, and c) Parallel Analysis Scree Plot (32). Items with factor loading values of 0.3 or greater were considered appropriate. Based on the three-indicator rules, at least three items must exist for each factor and the presence of a single item in the factor was estimated approximately 0.3 based on the formula $C V=5.152 \div \sqrt{ }(n-2)$, (in this formula, the ' $C V$ ' is the number of extractable factors and ' $n$ ' is the sample size) (33).

\subsubsection{Confirmatory Factor Analysis}

For this step the structure obtained through EFA was investigated by CFA. The most important objective of CFA is to determine the power of a predefined factor model, which in the present study was the same structure as obtained by EFA, with a set of observed data (34). In CFA, the model fitness was assessed according to the Parsimonious Normed Fit Index (PNFI), Parsimonious Comparative Fit Index (PCFI) and Adjusted Goodness of Fit Index (AGFI) (>0.5), Comparative of Fit Index (CFI) and Incremental Fit Index (IFI) $(>0.9)$, Root Mean Square Error of Approximation (RMSEA) (>0.08), and Minimum Discrepancy Function divided by Degrees of Freedom (CMIN/DF) (<3) (35).

\subsubsection{Convergent and divergent validity assessment}


CFA is a multimethod-multi-trait approach suitable for construct validity that covers convergent and divergent validity. In order to determine convergent and divergent validity, the correlation between variables was determined using AMOS software and then the weighted standardized regression table was determined. Finally, using Gaskin's coded Excel software, convergent and divergent validity was obtained (36). Convergent and divergent construct validity of the concept of loneliness was measured by the Fornell and Larker approach based on the following parameters: The Average Variance Extracted (AVE) and Maximum Shared Squared Variance (MSV). For convergent validity, the AVE should be greater than 0.5 , and for the divergent validity, the MSV must be less than AVE (37).

\subsection{Reliability assessment}

Reliability is actually the stability and repeatability of a tool. In this study, internal consistency was estimated using the Cronbach's alpha (a), McDonald's omega ( $\Omega$ ), and Average inter-item Correlation (AIC). Coefficients $\Omega$ and a values greater than 0.7 were acceptable (38). The AIC value between 0.2 and 0.4 indicated good internal consistency (30). The composite reliability (CR), which replaces Cronbach's alpha coefficient in structural equation modeling were evaluated. the CR values greater than 0.7 were considered acceptable (39).

\subsection{Multivariate normality and outliers}

Univariate distributions were examined for outliers, skewness, and kurtosis. Multivariate distributions were evaluated for normality and multivariate outliers. Multivariate normality can be assessed through the use of the Mardia's coefficient of multivariate kurtosis. One indication of deviation from a normal distribution is a Mardia's coefficient greater than 8 (40). Multivariate outliers were evaluated through the evaluation of a Mahalanobis distance. Items with a Mahalanobis distance of $p<.001$ were considered to be multivariate outliers (40). In this study all of the statistical analysis were performed by SPSS ${ }_{26}, \mathrm{SPSS}-\mathrm{R} \mathrm{menu}_{2}, \mathrm{AMOS}_{24}$ and $\mathrm{JASP}_{0.14 .0 .0}$ software.

\section{Ethics statement}

Ethical approval of this study was obtained from the Ethics Committee of Mazandaran University of Medical Sciences (Code: IR.MAZUMS.REC.1399.6682), Sari, Iran.

\section{Result}

\section{Demographic characteristics}

In the sample $(n=400)$ the mean age and standard deviation was $71.32(S D \pm 6.09)$ years. The majority of the sample were retired, married, men, with a high level of education and "high" economical level. Details of other demographic characteristics of participants are shown in Table 1. 
Table 1

Demographic characteristics of participants $(n=400)$

\begin{tabular}{|ll|}
\hline Variables & $\mathbf{N}(\%)$ \\
\hline Gender & $158(39.5)$ \\
\hline Female & $242(60.5)$ \\
\hline Male & \\
\hline Marital status & $29(7.3)$ \\
\hline Single & $331(82.8)$ \\
\hline Married & $13(3.3)$ \\
Divorced & $27(6.8)$ \\
\hline Widow & \\
\hline Education level & $4.5(18)$ \\
\hline Illiterate & $81(20.3)$ \\
Less than diploma & $80(20.0)$ \\
\hline Diploma & $221(55.3)$ \\
\hline Academic & \\
\hline Employment & $24(6.0)$ \\
\hline Unemployed & $105(26.3)$ \\
\hline Employed & $172(43.0)$ \\
\hline Retired & $56(14.0)$ \\
Housewife & $43(10.8)$ \\
\hline Free work & $227(56.8)$ \\
\hline Economic status & \\
\hline Low & $44(11.0)$ \\
\hline Medium & \\
\hline Number of children & \\
\hline
\end{tabular}




\begin{tabular}{|ll|}
\hline Variables & $\mathbf{N}(\%)$ \\
\hline One & $42(10.5)$ \\
Two & $132(33.0)$ \\
Three & $90(22.5)$ \\
Four and more & $92(23.0)$ \\
\hline
\end{tabular}

\section{Face and content validity}

Based on the result of face validity, all items of the scale are appropriate, clear and relevance for using. In addition, the content validity using CVR of all items were appropriate according to Lawshe table and kappa coefficient $(\mathrm{K})$ of all items were higher than 0.75 .

\section{Construct validity}

The results of MLEFA showed that the KMO test value was 0.817 and Bartlett's test value was 1018.910 ( $P$ $<0.001)$. It also revealed two factor extracted in MLEFA approach for Loneliness Scale. See details in figure no. $1,2,3$. These two factors (factor one with items of $1,4,7,8,11$ and factor two with items of 2,5,9) identified in the EFA of the present study confirmed the dimensions of the original loneliness scale with explained total variance of $45.66 \%$ in this sample. Four items (items of $3,6,10,12$ ) of the original scale extracted in EFA because their factor loading were lower than 0.3. The details of eigenvalues and percent of variances of these two factors are shown in Table 2. 
Table 2

Exploratory factors extracted of De Jong Gierveld Loneliness Scale $(n=200)$

\begin{tabular}{|c|c|c|c|c|c|}
\hline Factors & $Q_{n}$. Item & $\begin{array}{l}\text { Factor } \\
\text { loading }\end{array}$ & $h^{2}$ & Eigenvalue & \%Variance \\
\hline \multirow[t]{5}{*}{$\begin{array}{l}\text { Social } \\
\text { loneliness }\end{array}$} & $\begin{array}{l}\text { 8. There are enough people I feel } \\
\text { close to. }\end{array}$ & 0.846 & 0.699 & \multirow[t]{5}{*}{2.77} & \multirow[t]{5}{*}{30.84} \\
\hline & $\begin{array}{l}\text { 7. There are many people I can trust } \\
\text { completely. }\end{array}$ & 0.741 & 0.540 & & \\
\hline & $\begin{array}{l}\text { 4. There are plenty of people I can } \\
\text { lean on when I have problems. }\end{array}$ & 0.701 & 0.502 & & \\
\hline & $\begin{array}{l}11 . \text { I can call on my friends whenever I } \\
\text { need them. }\end{array}$ & 0.669 & 0.447 & & \\
\hline & $\begin{array}{l}\text { 1. There is always someone I can talk } \\
\text { to about my day-to-day problems. }\end{array}$ & 0.538 & 0.293 & & \\
\hline \multirow[t]{3}{*}{$\begin{array}{l}\text { Emotional } \\
\text { loneliness }\end{array}$} & $\begin{array}{l}\text { 5. I miss the pleasure of the company } \\
\text { of others. }\end{array}$ & 0.799 & 0.637 & \multirow[t]{3}{*}{1.33} & \multirow[t]{3}{*}{14.81} \\
\hline & 9. I miss having people around me & 0.657 & 0.416 & & \\
\hline & 2. I miss having a really close friend. & 0.571 & 0.371 & & \\
\hline
\end{tabular}

Based on results of the CFA, the extracted model after was confirmed by all goodness of fit indices. Details of these indices are shown in Table 3 and Fig. 4. Also, reliability of the two factors of this scale was excellent based on the Cronbach's alpha, McDonald's omega, CR. Details of these indices are shown in Table 4. As well as the AIC values of factors were good. Based on results of convergent validity, the AVE of two factors was more than the MSV and shows that the factors have good convergent, but no discriminant validity (Table 4). 
Table 3

Fit indices of the CFA Model after Structure Modification of the Persian Loneliness Scale $(n=200)$

\begin{tabular}{|c|c|c|c|c|c|c|c|c|c|c|}
\hline Indices & $x^{2}$ & df & $\begin{array}{l}P \\
\text { value }\end{array}$ & CMIN/DF & $\begin{array}{l}\text { RMSEA } \\
\text { (CI90\%) }\end{array}$ & PNFI & PCFI & TLI & IFI & CFI \\
\hline $\begin{array}{l}\text { CFA Model } \\
\text { after } \\
\text { Structure } \\
\text { Modification }\end{array}$ & 28.570 & 19 & $<.0001$ & 1.50 & $\begin{array}{l}.036 \\
(.000 \text { to } \\
.061)\end{array}$ & .658 & .671 & .985 & .990 & .990 \\
\hline \multicolumn{11}{|c|}{$\begin{array}{l}\text { DF: Degree of freedom; PCFI: Parsimonious Comparative Fit Index; PNFI: Parsimonious Normed Fit } \\
\text { Index; CMIN/DF: Minimum Discrepancy Function divided by Degrees of Freedom; RMSEA: Root Mean } \\
\text { Square Error of Approximation; TLI: Tuker-Lewis Index; and CFI: Comparative Fit Index, IFI: Incremental } \\
\text { Fit Index }\end{array}$} \\
\hline \multicolumn{11}{|c|}{$\begin{array}{l}\text { Fitness indexes: PNFI, PCFI (>0.5); TLI, IFI, CFI (>0.9), RMSEA ( } ₫ 0.08), \text { CMIN/DF ( } ₫ 3 \text { good, } ₫ 5 \\
\text { acceptable) }\end{array}$} \\
\hline
\end{tabular}

Table 4

The indices of the convergent, discriminant validity, and internal consistency of Loneliness Scale $(n=400)$

\begin{tabular}{|lllllll|}
\hline & CR & AVE & MSV & Alpha [CI95\%] & Omega & AIC \\
\hline Social loneliness & 0.851 & 0.493 & -0.17 & $.822(.79$ to .84$)$ & .828 & .484 \\
\hline Emotional loneliness & 0.763 & 0.464 & -0.17 & $.711(.65$ to .75$)$ & .719 & .454 \\
\hline
\end{tabular}

\section{Discussion}

In this study, we assessed the psychometric properties of the Persian version of the Loneliness Scale among an Iranian older adults population during the COVID-19 pandemic. The result explained $45.66 \%$ of the total variance of the Loneliness Scale. Since the two factors were eventually extracted, these is two factors did not have discriminant validity. Furthermore, based on our results, the Persian version of the Loneliness Scale showed a clear factor structure with two factors, namely social loneliness ( 5 items) and emotional loneliness ( 3 items). All reliability indices such as Cronbach's alpha, McDonald's omega, CR, and maximal reliability were excellent for these two subscales.

The first factor of this scale is 'social loneliness' with 5 items refers to a lack of social networks. It is noteworthy that items of social loneliness factor confirmed in confirmatory factor analysis, is identical to the original scale items in this sample. According to Weis (1973), social loneliness means the lack of a network of social relationships in which a person is part of a group of friends who share common interests such as their feelings, ideas, dreams and activities (17). One study has shown that older adults who have retired from their professional lives may experience more social loneliness (41). Moreover, during COVID-19 pandemic, the WHO has advised to maintain social distance, quarantine, and self-isolation to reduce the 
prevalence of this disease in the population, especially in vulnerable groups including of older adults (6). Then the rate of social relationships will decrease among people especially older adults. This in turn can make them more vulnerable. Thus amplifies the chance of developing several negative outcomes such as depression, distress, anxiety, decreasing life satisfaction among this population during quarantine for COVID-19 pandemic $(14,15)$. Therefore, it is important to pay attention to loneliness.

The second factor of this scale is 'emotional loneliness' consisting of 3 items that refers to a lack of close and intimate attachment to another person (41). According to Weis (1973), persons who experience emotional loneliness means that the individual misses others. This often occurs after losing a close emotional attachment through divorce or death of a partner (42). Recent studies have shown that emotional loneliness is more harmful to health than social loneliness, and this can cause problems such as feelings of aloneness, anxiety, hypervigilance, high sensitivity to minimal cues, and feelings of abandonment (19). In study of Súilleabháin and Steptoe emotional loneliness in older adults living alone is significantly associated with an increased risk of mortality (19). It is noteworthy that out of the total items of this subscale of the original scale, three items refer to missing someone. Given quarantine of these individuals in this pandemic situation, our finding during EFA and CFA extracted these three items for this subscale. In fact, it shows the impact has on these people in losing their emotional relationships with their relatives.

\section{Implication}

According to the results of this study, the social dimension loneliness has a significant impact on health and quality of life of older adults. This was especially true during quarantine, clinical settings of health care need to suitable scale to identify those who suffer the resultant of the negative health impacts of loneliness and target interventions to improve their social conditions. This study provides a suitable scale for researchers and health care practitioner for translating research into practice and refine, modify and deliver interventions based on the complexity of loneliness among older adults during COVID-19 pandemic.

\section{Limitation}

The most important limitations of this study resulted from online data collection during the COVID-19 pandemic. Therefore, people who did not have access to the internet or social networks were inevitably excluded from the study. It is possible that older adult who were technically less astute may have been under represented in this sample. This sample may therefore not be representative of all older adults.

\section{Conclusion}

Based on this study, we concluded that Persian version of the loneliness scale can detect and distinct two dimension of loneliness such as social loneliness and emotional loneliness in older adults population. But the remarkable thing is that this scale can identify the social loneliness more powerfully than the emotional loneliness in this population. 


\section{Abbreviations}

CVR: content validity ratios; CVI: content validity index; EFA: Exploratory Factor Analysis; CFA: Confirmatory Factor Analysis; MLEFA: Maximum Likelihood Exploratory Factor Analysis; KMO: Kaiser-Meyer-Olkin; Cls: confidence intervals; EGA: Exploratory Graph Analysis; PNFI: Parsimonious Normed Fit Index; PCFI: Parsimonious Comparative Fit Index; AGFI: Adjusted Goodness of Fit Index; CFI: Comparative of Fit Index; IFI: Incremental Fit Index; RMSEA: Root Mean Square Error of Approximation; CMIN/DF: Minimum Discrepancy Function divided by Degrees of Freedom; AVE: Average Variance Extracted; MSV: Maximum Shared Squared Variance; AIC: Average inter-item Correlation; CR: composite reliability

\section{Declarations}

\section{Ethics approval and consent to participate}

This study was approved by the ethical committee of the Mazandaran University of Medical Sciences (Code: IR.MAZUMS.REC.1399.6682), Sari, Iran. Based on the Declaration of Helsinki, We informed all of the participants about the purposes and procedures of this study and we assured them that participation in this study is voluntary. The informed consent was obtained from all participants. The study findings would be reported and published anonymously.

\section{Consent for publication}

Not applicable

\section{Availability of data and materials}

The datasets generated and analysed during the current study are available from the corresponding author on reasonable request.

\section{Competing interests}

The authors report no competing of interest in this work.

\section{Funding}

Not applicable

\section{Authors' contributions}


MAF and LH designed the study and collected the data and drafted the manuscrip. HSN analysed the data. ESF read and approved the final manuscript.

\section{Acknowledgements}

We thank all the participants who took part in the study.

\section{Author Details}

${ }^{1}$ School of Nursing and Midwifery, Iran University of Medical Sciences, Tehran, Iran, ${ }^{2}$ Assistant Professor, School of Nursing and Midwifery Amol, Mazandaran University of Medical Sciences, Sari, Iran, ${ }^{3}$ Professor Emeritus, Department of Physiological Nursing, School of Nursing, and Department of Epidemiology \& Biostatistics, School of Medicine, University of California Sand Francisco, San Francisco, California, USA, 4 Center for Nursing Care Research, School of Nursing and Midwifery, Iran University of Medical Sciences.

\section{References}

1. Wilder-Smith A, Chiew CJ, Lee VJ. Can we contain the COVID-19 outbreak with the same measures as for SARS? The Lancet Infectious Diseases. 2020.

2. Salimi R, Gomar R, Heshmati B. The COVID-19 outbreak in Iran. Journal of global health. 2020;10(1).

3. Raoofi A, Takian A, Sari AA, Olyaeemanesh A, Haghighi H, Aarabi M. COVID-19 pandemic and comparative health policy learning in Iran. Archives of Iranian Medicine. 2020;23(4):220-34.

4. Ghanbari B. On forecasting the spread of the COVID-19 in Iran: The second wave. Chaos, Solitons \& Fractals. 2020;140:110176.

5. Wang C, Horby PW, Hayden FG, Gao GF. A novel coronavirus outbreak of global health concern. The Lancet. 2020;395(10223):470-3.

6. Shati M, Alami A, Mortazavi SS, Eybpoosh S, Emamian MH, Moghadam M. Adherence to Self-isolation measures by older adults during coronavirus disease 2019 (COVID-19) epidemic: A phone survey in Iran. Medical Journal of The Islamic Republic of Iran (MJIRI). 2020;34(1):1044-9.

7. Benke C, Autenrieth LK, Asselmann E, Pané-Farré CA. Lockdown, quarantine measures, and social distancing: Associations with depression, anxiety and distress at the beginning of the COVID-19 pandemic among adults from Germany. Psychiatry Research. 2020:113462.

8. Luchetti M, Lee JH, Aschwanden D, Sesker A, Strickhouser JE, Terracciano A, et al. The trajectory of loneliness in response to COVID-19. American Psychologist. 2020.

9. Palgi Y, Shrira A, Ring L, Bodner E, Avidor S, Bergman Y, et al. The loneliness pandemic: Loneliness and other concomitants of depression, anxiety and their comorbidity during the COVID-19 outbreak. Journal of Affective Disorders. 2020. 
10. Anderson GO, Thayer CE. Loneliness and social connections: A national survey of adults 45 and older. Washington, DC: AARP Foundation. 2018.

11. National Academies of Sciences E, Medicine. Social Isolation and Loneliness in Older Adults: Opportunities for the Health Care System. 2020.

12. Jaremka LM, Fagundes CP, Glaser R, Bennett JM, Malarkey WB, Kiecolt-Glaser JK. Loneliness predicts pain, depression, and fatigue: understanding the role of immune dysregulation.

Psychoneuroendocrinology. 2013;38(8):1310-7.

13. Şar AH, Göktürk GY, Tura G, Kazaz N. Is the Internet use an effective method to cope with elderly loneliness and decrease loneliness symptom? Procedia-Social and Behavioral Sciences. 2012;55:1053-9.

14. Penning MJ, Liu G, Chou PHB. Measuring loneliness among middle-aged and older adults: the UCLA and de Jong Gierveld Loneliness Scales. Social Indicators Research. 2014;118(3):1147-66.

15. Liu B, Floud S. Unravelling the associations between social isolation, loneliness, and mortality. The Lancet Public Health. 2017;2(6):e248-e9.

16. Poscia A, Stojanovic J, La Milia DI, Duplaga M, Grysztar M, Moscato U, et al. Interventions targeting loneliness and social isolation among the older people: An update systematic review. Experimental gerontology. 2018;102:133-44.

17. Weiss RS. Loneliness: The experience of emotional and social isolation. 1973.

18. Peerenboom L, Collard R, Naarding P, Comijs H. The association between depression and emotional and social loneliness in older persons and the influence of social support, cognitive functioning and personality: A cross-sectional study. Journal of affective disorders. 2015;182:26-31.

19. O'Súilleabháin PS, Gallagher S, Steptoe A. Loneliness, living alone, and all-cause mortality: The role of emotional and social loneliness in the elderly during 19 years of follow-up. Psychosomatic medicine. 2019;81(6):521.

20. De Jong-Gierveld J, Kamphuls F. The development of a Rasch-type loneliness scale. Applied psychological measurement. 1985;9(3):289-99.

21. Rezaeipandari H, Ravaei J, Bahrevar V, Mirrezaei S, Morowatisharifabad MA. Social participation and loneliness among older adults in Yazd, Iran. Health \& Social Care in the Community. 2020.

22. Salimi A. Social-emotional loneliness and life satisfaction. Procedia-Social and Behavioral Sciences. 2011;29:292-5.

23. de Jong Gierveld J, van Tilburg T, Dykstra P. Loneliness and social isolation: new ways of theorizing and conducting research. 2018.

24. Nilsson J, Gardulf A, Lepp M. Process of translation and adaptation of the Nurse Professional Competence (NPC) Scale. Journal of Nursing Education and Practice. 2016;6(1):100.

25. Rust J, Golombok S. Modern psychometrics: The science of psychological assessment: Routledge; 2014.

26. Cook DA, Beckman TJ. Current concepts in validity and reliability for psychometric instruments: theory and application. The American journal of medicine. 2006;119(2):166. e7-. e16. 
27. Sharif Nia H, Pahlevan Sharif S, Lehto RH, Boyle C, Yaghoobzadeh A, Kaveh O, et al. Development and psychometric evaluation of a Persian version of the Death Depression Scale-Revised: a cross-cultural adaptation for patients with advanced cancer. Japanese journal of clinical oncology. 2017;47(8):7139.

28. Lawshe CH. A quantitative approach to content validity 1. Personnel psychology. 1975;28(4):563-75.

29. Ebadi A, Zarshenas L, Rakhshan M, Zareiyan A, Sharifnia S, Mojahedi M. Principles of scale development in health science. Tehran: jamee negar. 2017.

30. Mohammadbeigi A, Mohammadsalehi N, Aligol M. Validity and reliability of the instruments and types of measurments in health applied researches. Journal of rafsanjan university of medical sciences. 2015;13(12):1153-70.

31. Çokluk Ö, Koçak D. Using Horn's Parallel Analysis Method in Exploratory Factor Analysis for Determining the Number of Factors. Educational Sciences: Theory and Practice. 2016;16(2):537-51.

32. Golino HF, Epskamp S. Exploratory graph analysis: A new approach for estimating the number of dimensions in psychological research. PloS one. 2017;12(6):e0174035.

33. Pahlevan Sharif S, Sharif Nia H. Structural equation modeling with AMOS. Artin Teb, Tehran. 2018.

34. Hooper D, Coughlan J, Mullen MR. Structural equation modelling: Guidelines for determining model fit. Electronic journal of business research methods. 2008;6(1):53-60.

35. Meyers LS, Gamst G, Guarino AJ. Applied multivariate research: Design and interpretation: Sage publications; 2016.

36. Gaskin J. Validity master. Stats Tools Package http://statwiki kolobkreations com. 2012.

37. Fornell C, Larcker DF. Evaluating structural equation models with unobservable variables and measurement error. Journal of marketing research. 1981;18(1):39-50.

38. Mayers A. Introduction to statistics and SPSS in psychology: Pearson Higher Ed; 2013.

39. Sharif Nia H, Shafipour V, Allen K-A, Heidari MR, Yazdani-Charati J, Zareiyan A. A Second-Order Confirmatory Factor Analysis of the Moral Distress Scale-Revised for Nurses. Nursing ethics. 2019;26(4):1199-210.

40. Wong H. Handbook of Partial Least Squares: Concepts, Methods and Applications: Springer Handbooks of Computational Statistics Series. Springer Science \& Business Media, 2010. 2010.

41. Liu L, Gou Z, Zuo J. Social support mediates loneliness and depression in elderly people. Journal of health psychology. 2016;21(5):750-8.

42. Diehl K, Jansen C, Ishchanova K, Hilger-Kolb J. Loneliness at universities: determinants of emotional and social loneliness among students. International journal of environmental research and public health. 2018;15(9):1865.

\section{Figures}




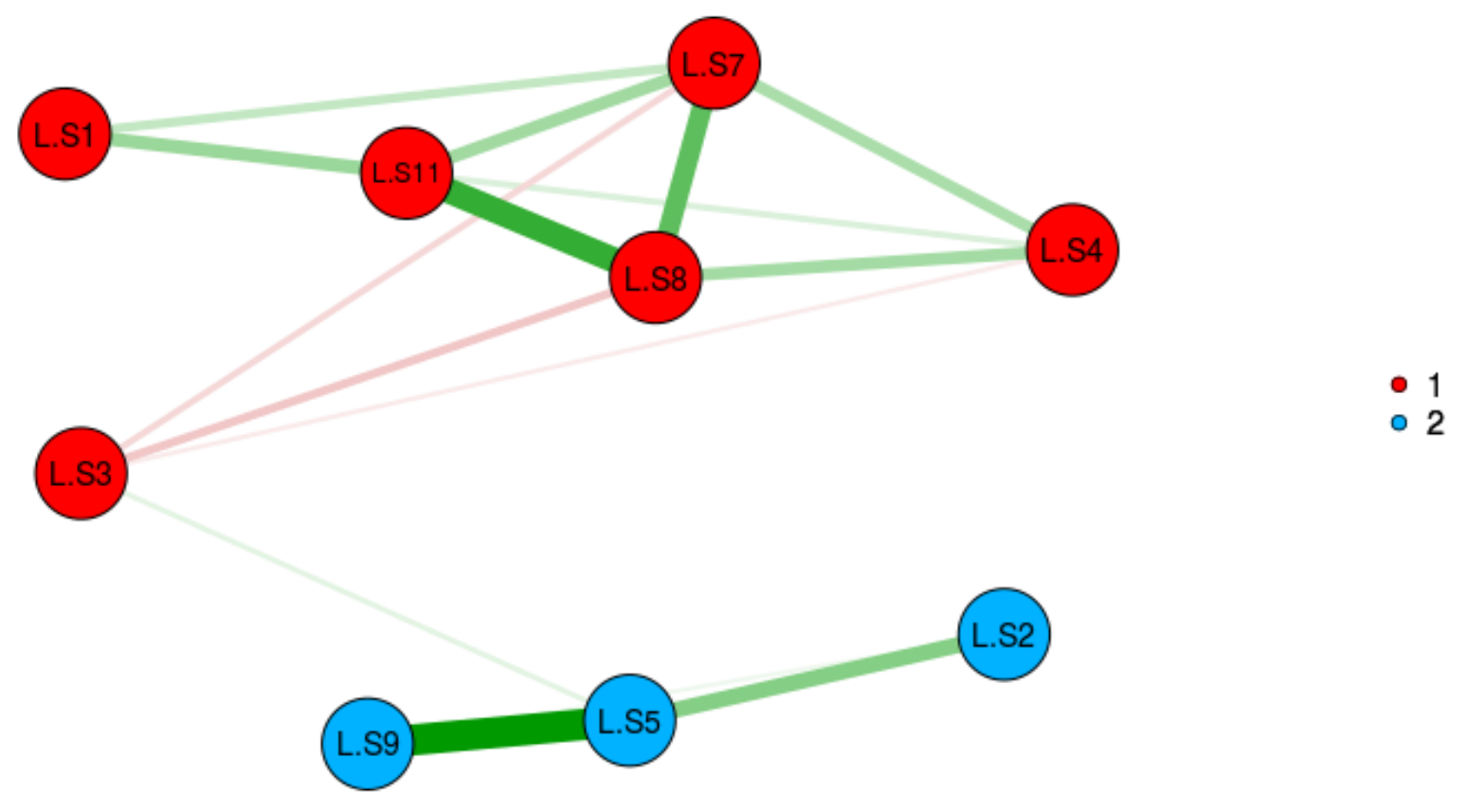

Figure 1

Exploratory Graph Analysis

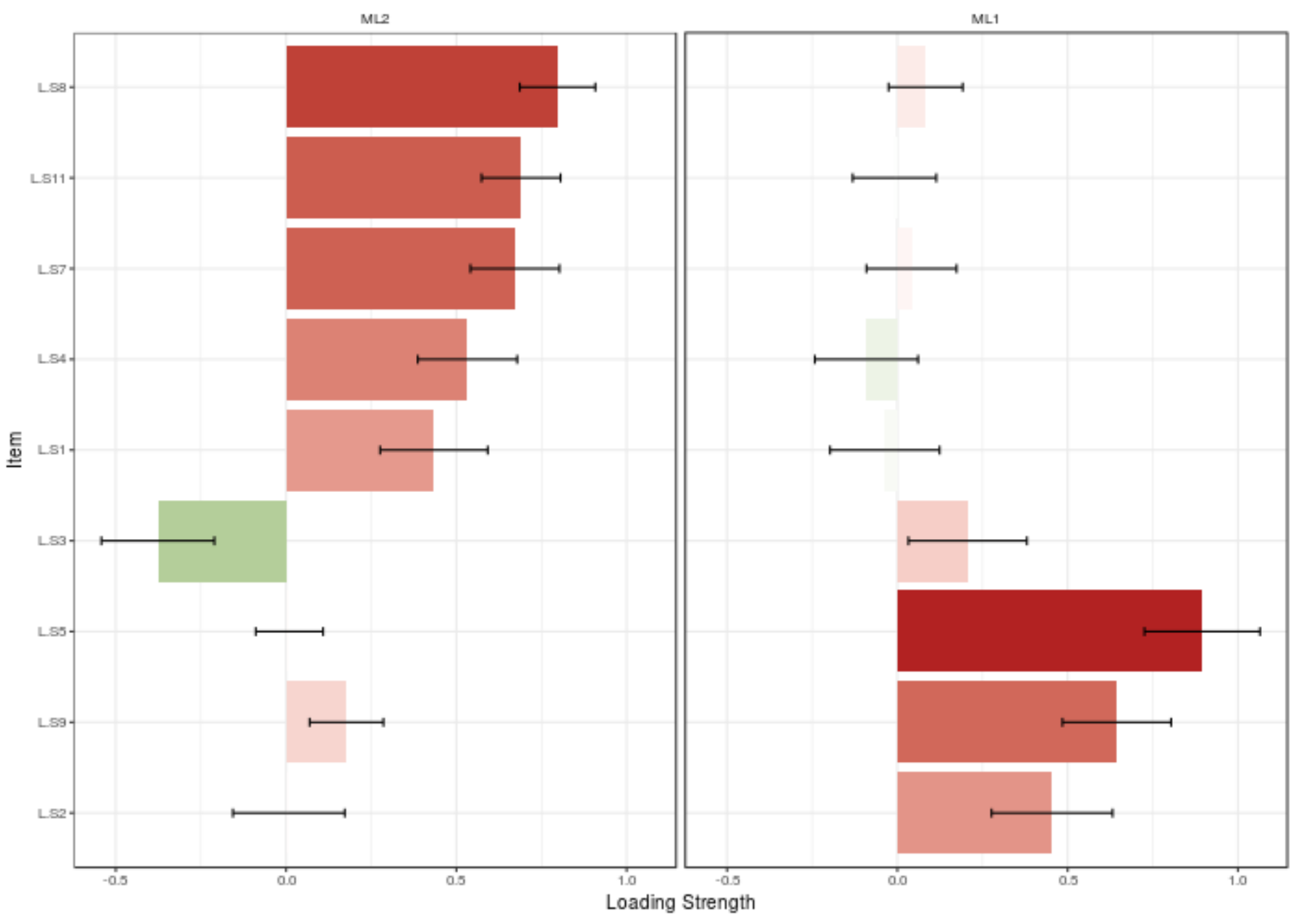

Page 17/19 
Figure 2

Loading strength of items in factors

Scree Plots : Parallel Analysis

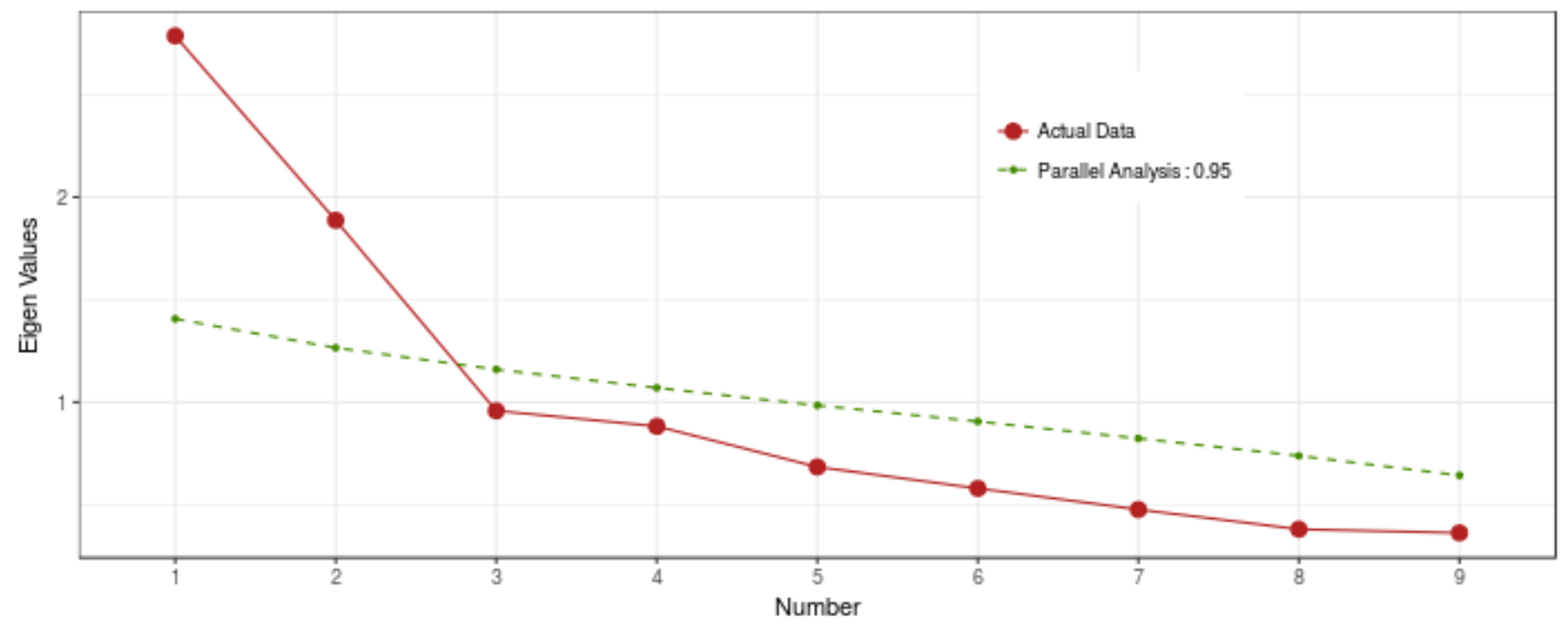

Figure 3

The parallel analysis scree plot 


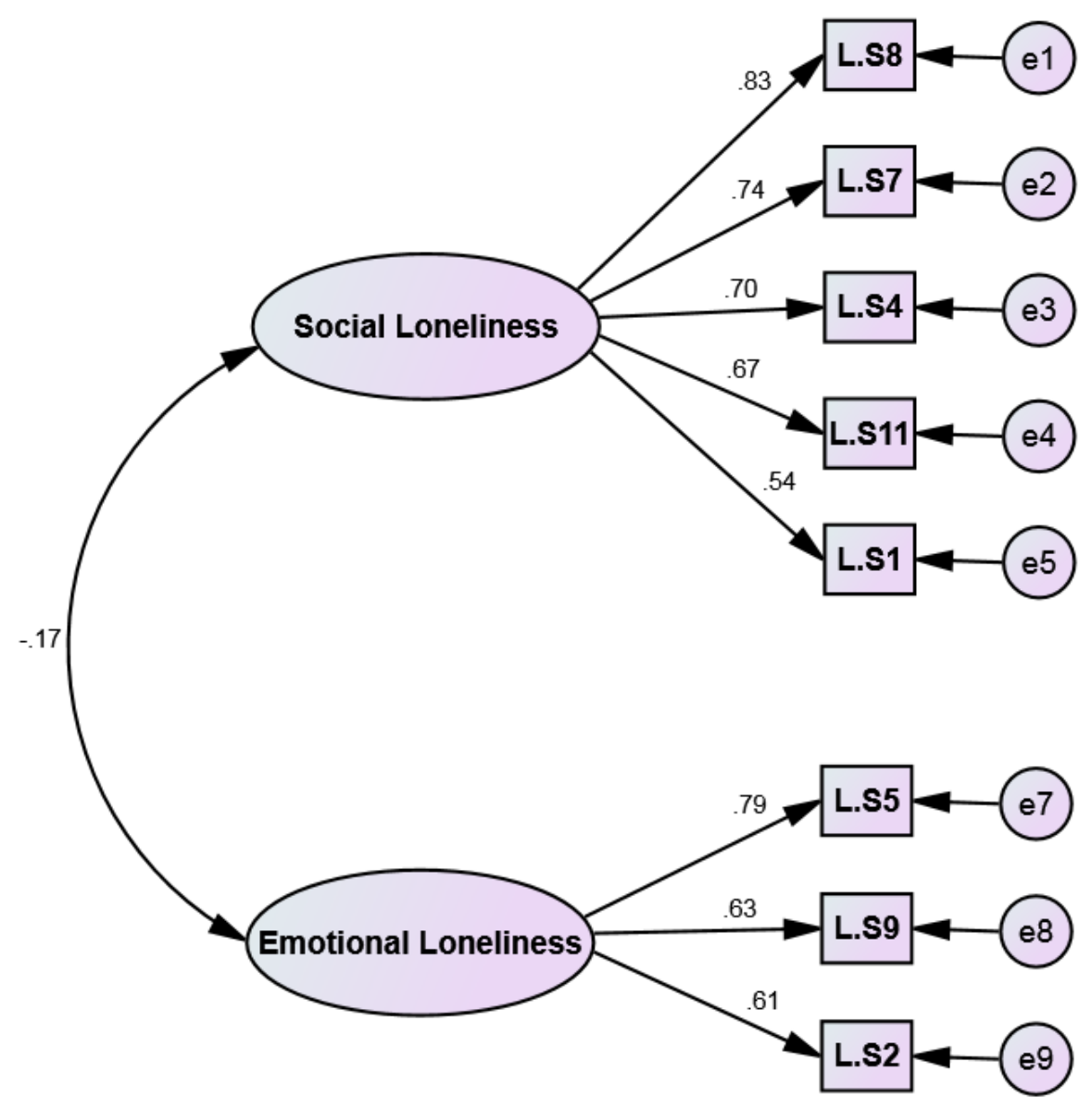

Figure 4

First order CFA of De Jong Gierveld Loneliness Scale $(n=200)$ 